\title{
Architectural Design by Considering Communication Systems with Observer (Case Study: KLIA Internasional Airport)
}

\author{
Imam Faisal Pane ${ }^{1,2}$, Hilma T Fachrudin ${ }^{1}$, Hesti Fibriasari ${ }^{3}$, Aurora S Lubis ${ }^{1,2}$ \\ 1. Department of Architecture, Faculty of Engineering, Universitas Sumatera Utara, Medan, Indonesia \\ 2. Laboratory History, Theory, and Criticism of Architecture, Department of Architecture, Universitas \\ Sumatera Utara, Medan, Indonesia \\ 3. Department of Foreign Language, Universitas Negeri Medan, Medan, Indonesia \\ Email: imam.faisal@usu.ac.id
}

\begin{abstract}
:
The development of architecture along with the development of situations and conditions that exist in the community. In this postmodernism era, architectural design is not only based on one paradigm, but is more free to choose the architectural design figure that will be achieved. The development of this infinite design can be studied or appreciated through a communication approach between an architectural object and an observer. The architectural design of this era can have different meanings among observers. This proves that the communication system does not guarantee the meaning of a building. This system only runs that the building can be interpreted based on a communication system in the form of a sign like the one in Semiotics. Using qualitative and quantitative descriptive methods in seeing the current development of architecture. This gives the conclusion that architectural design not only has a meaning but many meanings in accordance with the design paradigm used.
\end{abstract}

Keywords:

semiotics; architectural design; KLIA airport

\section{Introduction}

Architectural design is one of the products of people who work as architects (Little, 1939). Architectural design (AD) was first published and discussed in a journal in 1930 with the title "Architectural Design and Construction" published by John Wiley \& Sons (Castle, 2010). This journal contains the technical design and construction standards of various buildings in Europe, especially England. This journal becomes an international standard and is continually updated and has the meaning of universalism which is the basic ideology of Modern Architecture that is more concerned with production and function than the meaning of design.

Later architectural developments entered the postmodern era, where architectural designs were strived to have meaning again by expanding human experience by using precedents and historical buildings. The basis of the thought of postmodern architecture movement is the philosophy of phenomenology as a communication system between subjects and objects as well as actions and reactions between one another. By Venturi, postmodern is defined as "decorated shed" or ordinary functional buildings that are beautified on the outside (Venturi, 1966), as an effort to restore meaning into the design. This view has a basis, namely that each historical journey in a particular culture has different forms of architecture from time to time can be a reference to architectural design in the hope of releasing deadlock or boredom towards modern architecture. The method of extending human experience and presenting the values of beauty inside and outside the building eventually became the axis of the postmodern architectural movement that considers architectural works not only as forms and building materials but also as cultural symbols and works of art (Pace, 2004). 
In this postmodern era, an architect designs for both the owner and the community, even for himself usually will enter a message of meaning that he understands in order to reach others. A set of messages is encoded into the appearance of the building as well as building complements (examples of ornaments). The codes must be understood by others (observers) or codes that are mutually agreed upon or understood in the socio-cultural community. Disagreement with the code and understanding will result in different interpretations or the observer's perception is not the same as what is meant by the architect. Therefore an architect must consider the principles of the communication system as a consideration for designing so that his work can be understood and accepted by the owner and the public.

On the other hand, differences in interpretation between observers are common, including differences between the intentions of messages manifested in the code and the observers' interpretations, positive or negative. In the sense that a design work can contain many meanings due to multiple interpretations from various walks of life. Therefore, this paper will explain the results of research on airport buildings, namely KLIA International Airport in Malaysia. The research is descriptive qualitative and quantitative, which compares the perceptions of various writings related to the building to show multi-interpretation and compare it with what was conveyed by the designer.

\section{Review of Literature}

\subsection{Communication Systems in Architecture}

The socio-cultural symbols of Aboriginal people cannot be understood by the Karosocial society or religious objects. One belief cannot be understood by other beliefs, unless the person studies or has already gained knowledge about the socio-cultural proficiency level. One's understanding of symbols is inherent in one's own social culture. The symbols that a person understands are those which have been mutually agreed upon and apply in the social and cultural order. In the study of genius loci by Norberg-Schulz, humans create places (space, character, spirit and meaning), involving visual appearance, complementary elements and symbolization of meaning associated with locality awareness. The complementary elements in question are the ornaments on the building. Therefore the purpose of works of art including architecture is to preserve and be able to transmit local meanings as well (Norberg-Schulz, 1980).

Each architectural gesture leads to the interpretation of the user / observer who is subject to the physical form, location and functional interests of the building because it is related to the association of meaning based on the personal lens of the user / observer. But on the other hand, it is difficult for architects to not even possibly influence communication by conveying universal meaning (Sondhi, 2015). Historically, linguistic communication and language itself are believed to be based on belief systems. It is considered "mere vocal labeling or additional communication superimposed on the order given" (Umberto, 1997).

Semiotics is related to the phenomenon of signs in all its abundance and variety: letters, pictures, texts, acoustics, road signs, verbal signs, movements, icons, symbols, allegories, logos, indexes, hieroglyphs, pictures, signs naturally, celestial signs and architectural objects among others. This involves the study of duality (objects) as markers and markers in the presence of references. The main concepts and conditions of meaning communication in semiotics and semiology are (Amos, 1982), (Harris, 1988).

1. Signifiers and signifieds; Sign consists of signifier and signified. In linguistics, a signifier is a spoken sound or set of letters (visual). Signified is the actual concept of the object. For 
example the word "goat" for the first time people do not recognize the word until someone shows a picture or an idea about the word (abstraction). The reality of the word's actual concept is the actual goat called the referent. Of course the reality will be different between the image of the actual goat and goat.

2. Difference; Symbols must have differences that can be compared, otherwise they will be joined in one unit.

3. Arbitrator; Significant and signified relationships are arbitrators, that is the sign maker and the observer or a community need to agree on a relationship between the signifier and the signified.

4. Parole and langue; Parole is the pronunciation that comes out of the individual while langue is what is understood together in the community.

5. Syntagm; is a linear sequence or pattern on linguistic objects. If the linear pattern is incomplete and not sequential then the object cannot be identified.

In addition to being related to signifier and signified, according to Umberto Eco, in a modern or utilitarian view, the sign system is divided into 2 , namely denotation and connotation, where denotation is the primary function and connotation is a secondary function. For example, the primary function of a column is as a structure of channeling force from the overlying load to the ground, while the secondary function is seen if the column is displayed as an aesthetic impression.

The concept of communication of meaning in semiotics and semiology by Saussure can be translated to architecture especially with the syntagm system, if it aligns the columns of Ancient Greece, as shown in Figure 1.
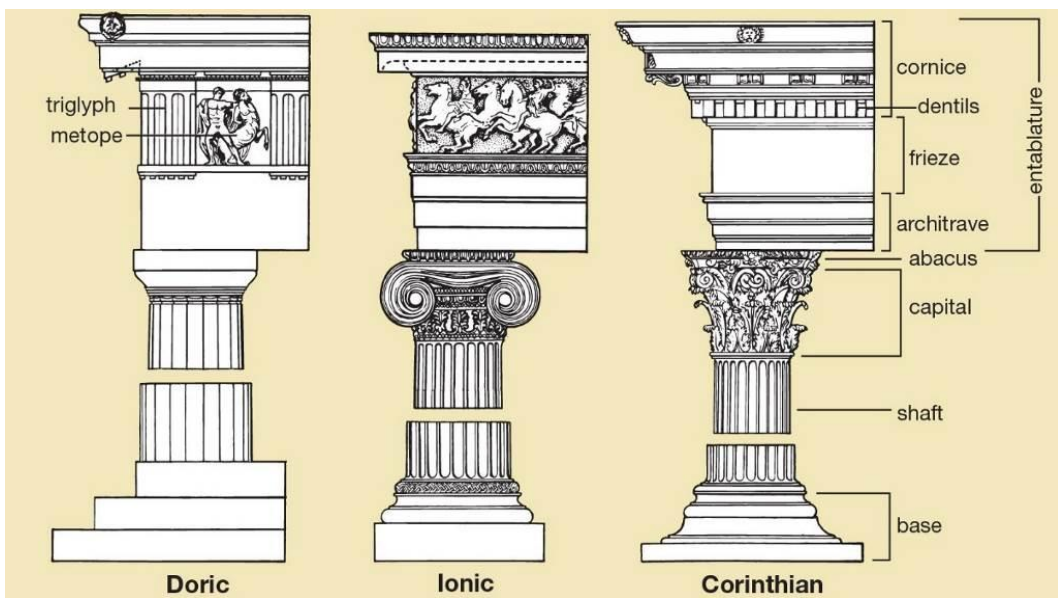

Figure 1. Column Order, Ancient Greece (I mage source: Encyclopedia Britannica)

\subsection{KLIA International Airport}

Kuala Lumpur International Airport (KLIA) was designed in 1992 by Kisho Kurokawa, a Japanese architect, and was completed in 1998, located $60 \mathrm{~km}$ south of the Malaysian city center, Kuala Lumpur. With an area of $100 \mathrm{~km} 2(10 \mathrm{~km}$ x $10 \mathrm{~km}), 10$ times larger than Narita Airport Japan. The design philosophy of the KLIA airport is to marry traditional Malaysian culture with sophisticated technology that is expected to function and grow well into the next century. This philosophy does not aim to combine the two aspects into one because it will weaken each identity. Kisho Kurokawa undertook a process of abstraction, alignment and interconnectedness, to enhance the potential of that separate identity. Abstraction cladding poles look like oil palm trees because Malaysia is the world's largest supplier of CPO. Inside the building, the pillars also 
function as air conditioning outlet points in airport spaces. Meanwhile, hyperbolic paraboloidshaped structure as a traditional dome representation of Islamic Architecture shows the link between the latest technology and Islamic traditions. In other words, the airport's architectural style is abstract-symbolic whose abstraction is taken from the modern idea of architecture with regard to geometric and symbolic taken from the Islamic tradition (Kurokawa, 1999).

KLIA International Airport is one part of the large-scale Malaysian national development project initiated by Mahathir Mohammad (Prime Minister of Malaysia) in the 1997-1999 period. Mahathir's ideas were based not only on economic acceleration (denotation) but also on building national icons and pride (connotation) with a political approach and cultural identity.

The tidal roof at the main terminal is reminiscent of Malaysian oil palm plantations supported by conical steel columns with natural skylights on them, abstractly reflecting the structure of palm oil (Mand, 2004). Malaysia was once the largest producer of palm oil in the world, which in 2006 was surpassed by Indonesia (Scientific American Board of Editors, 2012). Here we can see the correlation of the column abstraction in KLIA with oil palm so that it becomes a consideration of Kisho Kurokawa's design.

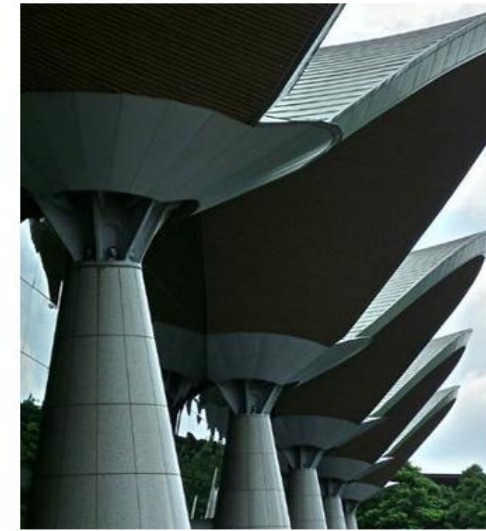

Figure 2. Column row KIIA in entrance

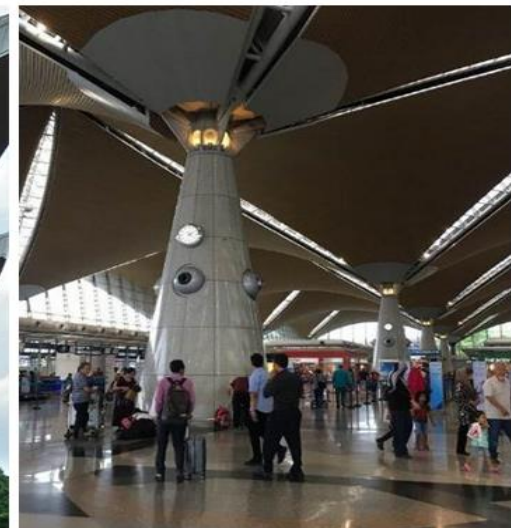

Figure 3. Column and tent roof, KIIA

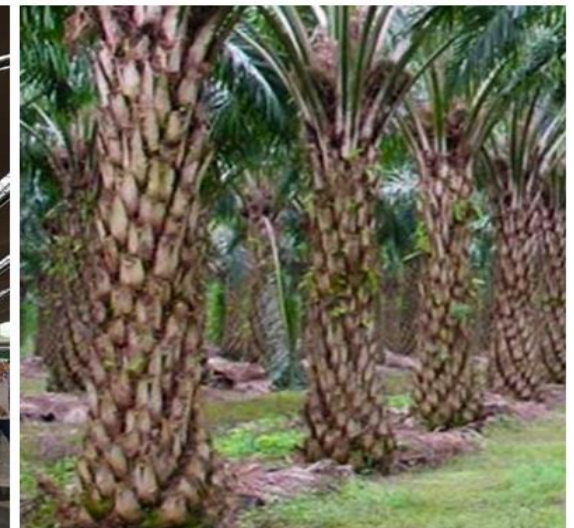

Figure 4. Palm tree (sounce: google.com)

\subsection{Abstraction in Architecture}

Abstraction in architecture can be applied to space and form. Abstraction is defined and used in modern architecture or called modern aesthetics, where complicated forms are simplified by eliminating traditional ornaments and details. Simplification can be in the form of the outline of the shape by giving certain colors in the boundary as done by Le Corbusier and Ludwig Mies van der Rohe (Vidler, 2000).

Abstraction is used in architecture education, especially when starting to pour ideas. Pictures consisting of lines form ideas from the reality to be realized. The types of abstraction consist of 3 types, namely: 1. formal abstraction; 2. functional abstraction; 3. semantic abstraction. The types of abstractions can be seen in Figure 05 to 07 (Gencosmanoglu, 2010).

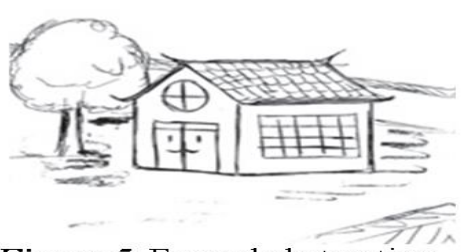

Figure 5. Formal abstraction

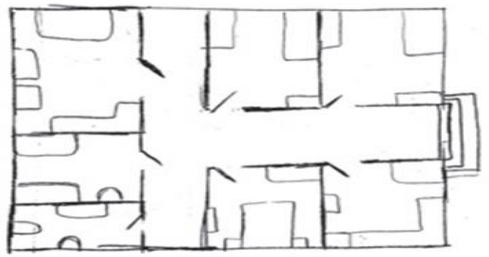

Figure 6. Functional abstraction

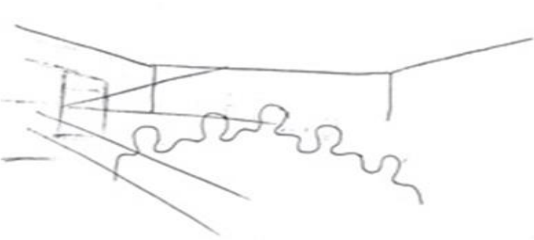

Figure 7. Semantic abstraction 


\section{Research Method}

In this study the method used is a mixed method, namely by using qualitative and quantitative descriptive. The qualitative method uses an inductive approach to formulate variables that will be examined based on the KLIA design approach by Kisho Kurokawa, especially on building columns (Sugiyono, 2004). The quantitative method is used with the confirmative communication approach through questionnaires, which is to see if there is a language similarity between the KLIA design ideas and the observer's perception.

The object of research will be focused on the column formation at KLIA designed by Kisho Kurokawa. The building will be explored through semiotics to see the architect's lingua which will later become a parole by observers. Meanwhile, the symbolism communication system through the abstraction (signifier-signified) is expected to explain the KLIA design method by Kisho Kurokawa.

It is hoped that this method can answer the existence of a communication system in architectural design, namely from the architect to the observer which also allows multiinterpretation. The object of research is focused on one of the building elements which has a double meaning as the hypothesis of semiotics theory that is signifier - signified on a single object (KLIA column). This part of the building will be discussed using existing architectural theory so that it can be more clearly understood in its architecture. This research method consists of several stages, namely: (a) The stage of data collection, (b) The stage of adjusting the theory, (c) Data analysis and drawing conclusions.

The questionnaire was aimed at first-degree students of Architecture at Universitas Sumatera Utara (USU) (94 respondents) who had not theoretically understood the basics and design concepts of Kisho Kurokawa at KLIA or had not yet gained knowledge about it. It is expected that the results of the questionnaire analysis will show the parole of respondents with Lingu Kisho Kurokawa.

\section{Discussions}

\subsection{Design Method Analysis}

Based on the literature review, it can be traced the method used by Kisho Kurokawa to design the KLIA column, as shown in table 01.

Table 1. Application of the Communication System in the design of the KLIA Column

\begin{tabular}{|c|c|c|c|c|c|}
\hline Langue & Signifier & Real Image & Signified & Syntagm & Design \\
\hline $\begin{array}{l}\text { - Malaysian } \\
\text { National } \\
\text { Pride } \\
\text { - The biggest } \\
\text { CPO } \\
\text { producer } \\
\text { (before 2006) }\end{array}$ & $\begin{array}{l}\text { Palm } \\
\text { tree }\end{array}$ & & 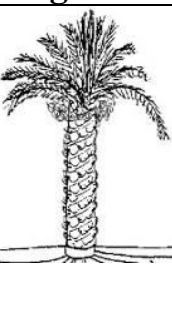 & $\begin{array}{l}\text { 1. Tree tunk } \\
\text { 2. Tree grove } \\
\text { 3. Limb } \\
\text { 4. Fruit brondol } \\
\text { 5. Branches and } \\
\text { leaves }\end{array}$ & \\
\hline
\end{tabular}

Based on table 1, it can be described that the langue received by Kisho Kurokawa from the Malaysian government is a national pride and considering that the building design was carried 
out before 2006, where Malaysia is the largest CPO producer in the world, while CPO comes from oil palm fruit produced from plantations. Malaysian plantation. The language agreed upon between the owner and Kisho Kurokawa (arbiter) is plantations and oil palm trees and Malaysian national pride manifests in them (connotation). The real image of the oil palm tree shown in table 01, real image, is the basis for Kisho Kurokawa to make an abstraction (idea) or signified.

Furthermore, the abstraction also contains syntagm like that of a real image. And in real design, the syntagm is also present sequentially. Even if observed closely, the tent roofs and rows of columns such as abstractions from oil palm plantations show branches and leaves between trees interlocking but the sun's rays remain.

On the body of the design column that decreases to the top, visible arrangement of a rectangular pattern as the difference abstraction of the pattern of the trunk of an oil palm tree that is formed from the fronds that have long been cut. While at the top the yellow light looks like an abstraction from oil palm fruit bunches (brondol).

\subsection{Respondens Perception}

In the previous discussion, it was explained how the langue between the owner and architect was extracted and became a form of model which then manifested in the reality in the form of KLIA columns. Based on the theory, KLIA's columns denotatively function as a roof load distributor and connotatively are the abstraction of oil palm trees as the pride of Malaysian national development. In this section I will explain the parole's perception of the respondents.

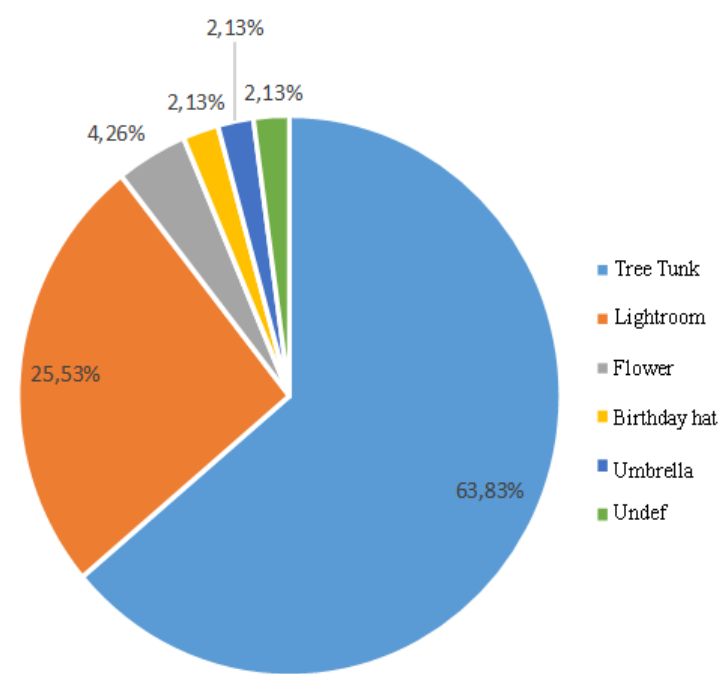

Figure 8. Chart of analysis of respondents' perceptions

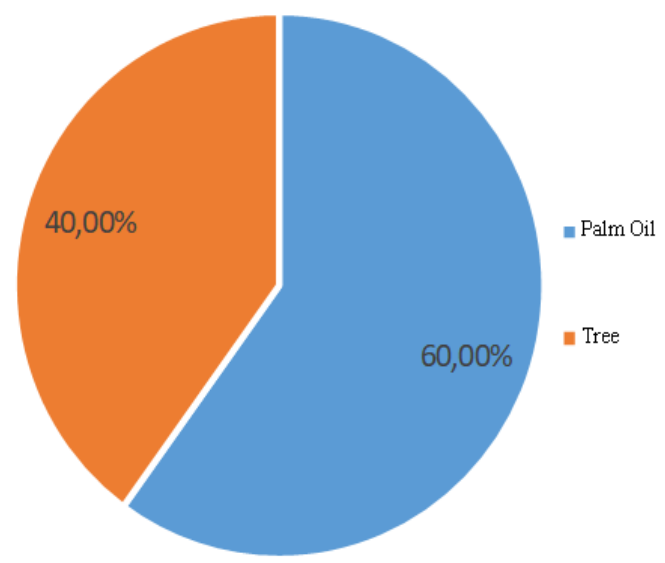

Figure 9. Tree type analysis chart

In Figure 8, it shows that more than half of respondents perceive the column's abstraction as a tree, and a quarter states the abstraction from the lighthouse. While in Figure 9, it shows that more than half of the respondents who think the KLIA column is a palm tree and the respondent correctly explained the sequence is a tree and the difference with other tree species.

\section{Conclusions}

Abstraction is an architectural style that emerged in modern architectural times to cover up the dryness of forms following a monotonous function (White, 2003), while modern architecture adheres to universality (Vidler, 2000). Based on the analysis results, half of all 
respondents understood langue as reflected in the KLIA columns as a tree (parole). And more than half accurately describe it as an oil palm tree. Considering that the respondent is not a Malaysian citizen, the Kurokawa design abstraction is quite successful as a tree, but it is not quite successful as a representation of an oil palm tree.

In Figure 8, you can see various interpretations of perception of the KLIA column, showing multi-interpretation can be generated from the method of abstraction. This is similar to what happened to the Le Corbusier church Nôtre-Dame-du-Haut, as seen in figure (Baumberger, 2009).
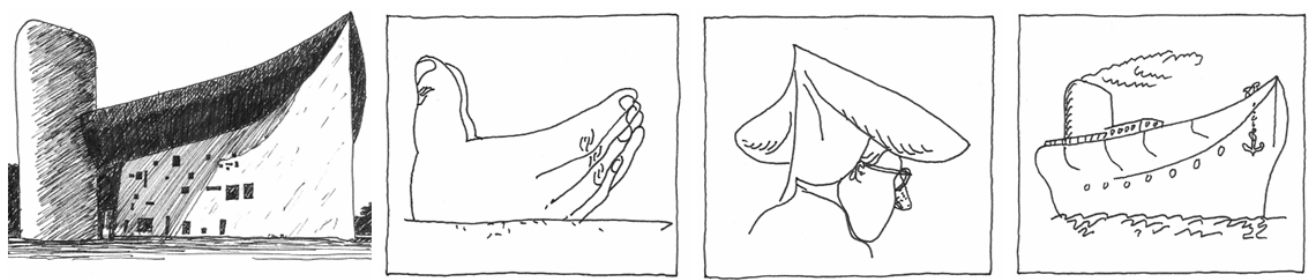

Figure 10. Multi-interpretation of the church Notre-Dame-du-Haut karya Le Corbusier (Baumberger, 2009)

But keep in mind that more than half of the respondents think that the KLIA column is a representation of a tree. While the 'tree' itself is a universal abstraction of all the trees on the face of the earth, apart from langue as an oil palm tree. It is clear that the theory by Sondhi which says it is almost impossible for meaning to be conveyed universally (Sondhi, 2015). Moreover all firstyear USU Architecture students did not know that Malaysia had been the largest CPO producer in the world before 2006.

The results of this study indicate that the abstraction communication system is almost ineffective in conveying the universal meaning, especially the universal meaning of an oil palm tree to Indonesian citizens with a note that Indonesia is currently the largest producer of CPO with the largest area of oil palm plantations in the world. Henceforth, research will be conducted on the perceptions of Malaysian citizens in order to get a local parole that shows that meaning has survived until now, even though Malaysia is no longer the largest CPO supplier in the world.

\section{Acknowledgments}

This article comes from research funded by RISTEKDIKTI with no. Contract Number: 11 / E1 / KP.PTNBH / 2019, March 29, 2019. Thank you to RISTEKDIKTI and all parties who support the implementation of this research.

\section{References}

Amos Rapoport (1982). The Meaning of the Built Environment. Beverley Hills, Sage Publications, Inc.

Baumberger, Christoph (2009). Ambiguity in Architecture. In book: From Logic to Art: Themes from Nelson Goodman. Publisher: Ontos. ResearchGate: https://www.researchgate.net/publication/309731646_Ambiguity_in_Architecture.

Castle, Helen (2010). Architectural Design and Construction Journal. John Wiley \& Sons, Inc.

Eco, U. 1980 Function and Sign: The Semiotics of Architecture. In Sign, Symbol and Architecture. New York: John Wiley \& Sons Ltd.

Feng, Ku A L (2009). Graphic Propaganda and National Identity in Malaya (1948-1960): A Social Semiotic Approach. Thesis, Universiti Sains Malaysia. 
Gencosmanoglu, Asu B. Nezor, S (2010). Criticizing architectural education through abstraction. ScienceDirect, Procedia Social and Behavioral Sciences 9. Elsevier Ltd.

Harris, Roy (1988). Language, Saussure and Wittgenstein. Routledge.

Ismail, Alice S. (2008). The Influence of Islamic Political Ideology on the Design of State Mosques in West Malaysia. Dissertation - Research Centre, Faculty of Built Environment and Engineering, Queensland University of Technology, Brisbane - Australia.

Kurokawa, Kishō. Sharp, Dennis. Slessor, Catherine. Ōhashi, Tomio (1999). Kisho Kurokawa: Kuala Lumpur International Airport. Edition Axel Menges. ISBN: 3930698242

Little, William (1939). The Shorter Oxford English Dictionary: On Historical Principles. Oxford University Press.

Mand, H. Mand, S (2004). Importing Technology, Constructing identity in a Global World; Kuala Lumpur International Airport (KLIA) Malaysia. Conference: Joint International Symposium on Globalization and Construction at Bangkok, Thailand.

Moleong, L. J. 2004 Metode Kajian Kualitatif. Bandung: Remaja Rosdakarya.

Norberg-Schulz, Christian 1980 Genius Loci: Towards a Phenomenology of Architecture, Rizzoli University of Michigan.

Nordin, T. Kechik, T (2012). Menelusuri Pemikiran Mantan Perdana Menteri Malaysia Melalui Karya Puisi: Ke Arah Model Pemerintahan Negara. Prosiding, Konferensi Internasional Kesusastraan XXII UNY - HISKI: "The Role of Literature in Enhancing Humanity and National Identity". Fakultas Bahasa dan Seni Universitas Negeri Yogyakarta \& Himpunan Sarjana Kesusastraan Indonesia (HISKI).

Pace, Anthony (2004). "Tarxien". In Daniel Cilia (ed.). Malta before History - The World's Oldest Free Standing Stone Architecture. Miranda Publishers. ISBN 978-9990985085.

Scientific American Board of Editors (2012), "The Other Oil Problem", Scientific American, 307 (6), p. 10, doi:10.1038/scientificamerican1212-10.

Sondhi, Priyanka (2015). Architecture as Communication: A Study of the role of Form, Function and Context in evoking Meaning. Thesis. Rochester Institute of Technology.

Sugiyono. 2009 Metoda Penelitian Kualitatif dan Kuantitatif dan R\&D. Bandung: CV. Alfabeta.

Umberto Eco (1997). Function and Sign: the Semiotics of architecture. (Rethinking Architecture - a reader in Cultural theory. London. Routledge, p 182.

Venturi, Robert (1966). Complexity and Contradiction in Architecture. New York: Museum of Modern Art.

Vidler, Anthony (2000). Diagrams of Diagrams: Architectural Abstraction and Modern Representation. JSTOR, Representations, No. 72. (Autumn, 2000), pp. 1-20

White, Michael. (2003). De Stijl and Dutch Modernism, Manchester: Manchester University Press. pp. 1 